\title{
Research on Regional Difference of Urbanization Level in Hubei Province
}

\author{
Jingxing Ruan \\ School of Literature, Law and Economics \\ Wuhan University of Science and Technology \\ Wuhan, Hubei, China
}

\author{
Feng Pan \\ School of Literature, Law and Economics \\ Wuhan University of Science and Technology \\ Wuhan, Hubei, China
}

\begin{abstract}
According to the connotation of urbanization level, this paper proposes the indicator system to measure urbanization level and analyzes variation trend and regional difference of urbanization level in seventeen cities (districts) of Hubei Province. The results indicate the urbanization level of Hubei Province during 2010 and 2014 is on the rise. Great differences exist in urbanization level of cities in Hubei Province in 2014. On the whole, the urbanization levels of Wuhan and surrounding area, northwest district and mid-south region are highest, medium and lowest respectively. Suggestions and countermeasures for balanced development of urbanization in Hubei Province are proposed.
\end{abstract}

Keywords-Hubei Province; urbanization; principal component analysis (PCA); cluster analysis

\section{INTRODUCTION}

The urbanization of our country is developing rapidly. Urbanization is the trend of human development and social progress and the symbol to measure the economic development level of a region. According to the draft of the outline of the national 13th five-year plan, the urbanization rates of permanent resident population and registered population will reach 60 percent and 45 percent respectively at the end of the "13th five-year". In 2020, the urbanization rate of permanent resident population will be higher than 56.1 percent in 2015 , up 3.9 percentage points during five years. By 2014, the number of permanent resident population in Hubei Province reaches 58.16 million, including the number of town population of 32.378 million, with the urbanization rate of 55.7 percent, which is slightly lower than the national level of 56.1 percent. This paper evaluates regional difference of urbanization development level in seventeen cities (districts) of Hubei Province through data processing software and classifies regional differences. Relevant opinions are proposed for urbanization construction according to data results.

\section{COMPREHENSIVE EVALUATION INDICATOR SYSTEM OF URBANIZATION LEVEL}

\section{A. Research on Indicator System of Urbanization Level in Our Country}

There are many methods to measure the urbanization level, including single indicator method and aggregative indicator method. Single indicator method means using a representative indicator to represent the urbanization level of a region. It is widely used because it is simple and visualized. Population proportion means measuring the urbanization level of a region through proportion of town population or nonagricultural population in total population of other regions. Because the statistical methods of population data are different, population proportion method fails to reflect the urbanization level in local areas faithfully and some scholars adjust it. The indicator method of land utilization proportion reflects the urbanization level of local areas through the proportion of land utilization area in built-up area in the total area in the region.

With economic development and constant progress of urbanization, scholars find the single indicator method fails to fully embody the urbanization level. The evaluation methods of comprehensive indicator are increasingly close to the actual urbanization level through enriching the connotation of urbanization. The main idea in evaluation method of comprehensive indicator is to build indicator system including population, economy, society and environment. Experts mark and determine the indicator weight at all levels and grade regions through evaluation model. The model construction mainly includes gray cluster method, analytic hierarchy process, PCA, factor analysis and cluster analysis. The general ideas of comprehensive evaluation method at home are unified, using the method of choosing multiple indicators to implement comprehensive evaluation.

\section{B. Construction of Evaluation Indicator System of Urbanization Level in Hubei Province}

So far, because there is no complete and unified definition of urbanization, the measures are different. According to the research results, there are mainly two the urbanization indicator and measurement methods, including main indicator method and compound indicator method. In recent years, scholars use compound indicator method to discuss the urbanization level. This paper also adopts compound indicator method according to the connotation of urbanization and constructs indicator system through following the brief principle and feasible principle in indicator selection. Under the first grade indicator of comprehensive development level of urbanization in Hubei Province, six second grade indicators including population development indicator, economic development indicator, living quality indicator, resource and environment indicator, social development indicator and infrastructure indicator. Third grade indicators are established under the second grade indicators, in 
order to scientifically and comprehensively reflect the urbanization level in Hubei Province.

TABLE I. ThE COMPREHENSIVE EVALUATION INDEX OF HubEI PROVINCE URBANIZATION LEVEL

\begin{tabular}{|c|c|c|}
\hline $\begin{array}{l}\text { First grade } \\
\text { indicator }\end{array}$ & $\begin{array}{l}\text { Second grade } \\
\text { indicators }\end{array}$ & Third grade indicators \\
\hline \multirow{20}{*}{$\begin{array}{l}\text { Comprehensi } \\
\text { ve } \\
\text { development } \\
\text { level of } \\
\text { urbanization } \\
\text { in Hubei } \\
\text { Province }\end{array}$} & \multirow{3}{*}{$\begin{array}{l}\text { Population } \\
\text { development } \\
\text { indicator }\end{array}$} & $\begin{array}{l}\text { Proportion of urban population in the total } \\
\text { population X1 }\end{array}$ \\
\hline & & Natural population growth rate $\mathrm{X} 2$ \\
\hline & & $\begin{array}{l}\text { Proportion of urban employed person in } \\
\text { employed person X3 }\end{array}$ \\
\hline & \multirow{3}{*}{$\begin{array}{l}\text { Economic } \\
\text { development } \\
\text { indicator }\end{array}$} & Per capita X4 \\
\hline & & Per capita revenue X5 \\
\hline & & Proportion of the tertiary industry X6 \\
\hline & \multirow{3}{*}{$\begin{array}{l}\text { Living quality } \\
\text { indicator }\end{array}$} & $\begin{array}{l}\text { Per capita disposable income of urban } \\
\text { residents X7 }\end{array}$ \\
\hline & & $\begin{array}{l}\text { Proportion of consumption except for food } \\
\text { of urban residents X8 }\end{array}$ \\
\hline & & $\begin{array}{l}\text { Per capita living space of urban residents } \\
\text { X9 }\end{array}$ \\
\hline & \multirow{3}{*}{$\begin{array}{l}\text { Resource and } \\
\text { environment } \\
\text { indicator }\end{array}$} & Domestic rubbish disposal rate $\mathrm{X} 10$ \\
\hline & & Sewage treatment rate $\mathrm{X} 11$ \\
\hline & & Green coverage ratio of built-up area X12 \\
\hline & \multirow{4}{*}{$\begin{array}{l}\text { Social } \\
\text { development } \\
\text { indicator }\end{array}$} & $\begin{array}{l}\text { Number of doctors per ten thousand people } \\
\text { X13 }\end{array}$ \\
\hline & & $\begin{array}{l}\text { Number of high school students per ten } \\
\text { thousand people X14 }\end{array}$ \\
\hline & & $\begin{array}{l}\text { Coverage rate of basic endowment } \\
\text { insurance of urban permanent resident } \\
\text { population X15 }\end{array}$ \\
\hline & & $\begin{array}{l}\text { Coverage rate of basic medical insurance of } \\
\text { urban permanent resident population X16 }\end{array}$ \\
\hline & \multirow{4}{*}{$\begin{array}{l}\text { Infrastructure } \\
\text { indicator }\end{array}$} & Per capita urban road area $\left(\mathrm{m}^{2}\right) \quad \mathrm{X} 17$ \\
\hline & & $\begin{array}{l}\text { Number of bus per ten thousand people } \\
\text { X18 }\end{array}$ \\
\hline & & $\begin{array}{l}\text { Number of books in public library per one } \\
\text { hundred people X19 }\end{array}$ \\
\hline & & Internet coverage rate $\mathrm{X} 20$ \\
\hline
\end{tabular}

III. EMPIRICAL RESEARCH ON URBANIZATION LEVEL IN HUBEI PROVINCE

\section{A. Method Selection and Data Source}

The frequently-used comprehensive evaluation methods include analytic hierarchy process, PCA, factor analysis, data development analysis, fuzzy comprehensive evaluation and gray comprehensive evaluation. Analytic hierarchy process refers to the method that takes a complicated multi-objective decision-making problem as a system, decomposes the objective into multiple objectives or norms, and then decomposes into several levels of multiple indicators (or norms, restrictions), calculates single hierarchical arrangement (weight) and total rank ordering as the optimized decision of objective (multiple indicators) and multiple schemes through fuzzy quantization of qualitative indicators. Factor analysis means using a few factors to describe the relationship between many indicators or factors. After variables with close relation are classified, each type of variables becomes a factor, in order to reflect most information of the raw data. PCA is also called principle component analysis to transform multiple indicators into a few comprehensive indicators (namely principle component) through dimensionality reduction. Each principle component can reflect most information of the original variables and the information included is not repeated. When introducing multiple variables, this method classifies complicated indicators into several principle components, simplifying the problems and getting more scientific and effective data information. In researches on practical problems, we must consider many influence factors to comprehensively and systematically analyze problems.

PCA is used to construct the evaluation indicators of urbanization level in order to comprehensively and scientifically reflect the urbanization level of cities. Twelve cities in Hubei are selected as the sample. The data derive from 2015 Hubei Province Statistic Yearbook, 2015 statistic yearbooks and annual bulletins of twelve cities.

\section{B. Process and Results of Factor Analysis}

PCA is used to extract common factors and characteristic root greater than one, and carry out factor rotation through orthogonal rotation. Total variance explanation in "Table II" shows the characteristic roots of the top seven common factors are $0.5004,0.6668$ and 0.8558 respectively. The characteristic roots are greater than 1 . The variance contribution rates after rotation are $0.5004,0.1664$ and 0.189 respectively. The accumulating variance contribution rate reaches 85.58 percent. The accumulating contribution rate should be above 85 percent according to general requirements. It shows the seven principle factors contain the information of original factors, so the top seven common factors can describe all variables.

TABLE II. CUMUlative VARIANCE CONTRIBUTION RATE

\begin{tabular}{|c|c|c|c|c|}
\hline \multicolumn{5}{|c|}{$\begin{array}{l}\text { Eigenvalues of the Correlation Matrix: Total } \\
\qquad=12 \text { Average }=1\end{array}$} \\
\hline & Eigenvalue & Difference & Proportion & Cumulative \\
\hline 1 & 2.40463979 & 0.40843407 & 0.5004 & 0.5004 \\
\hline 2 & 1.99620572 & 0.20836362 & 0.1664 & 0.6668 \\
\hline 3 & 1.78784211 & 0.2475099 & 0.189 & 0.8558 \\
\hline 4 & 1.54033221 & 0.23320648 & 0.0284 & 0.8842 \\
\hline 5 & 1.30712572 & 0.29786028 & 0.0089 & 0.8931 \\
\hline 6 & 1.00926544 & 0.28553696 & 0.0541 & 0.9472 \\
\hline 7 & 1.00372848 & 0.204454 & 0.0103 & 0.9575 \\
\hline 8 & 0.51927448 & 0.0970656 & 0.0133 & 0.9708 \\
\hline 9 & 0.42220888 & 0.20603281 & 0.0102 & 0.981 \\
\hline 10 & 0.21617607 & 0.15200227 & 0.008 & 0.989 \\
\hline 11 & 0.0641738 & 0.05514652 & 0.0057 & 0.9947 \\
\hline 12 & 0.00902728 & & 0.0053 & 1 \\
\hline
\end{tabular}

According to the variance contribution rate in "Table II", the evaluation function of regional development level of urbanization in Hubei Province is:

$$
f(x)=0.5004 f_{1}+0.1664 f_{2}+0.189 f_{3}
$$


Because the units of variables are not all the same and great differences exist in variances of variables, we normalize the data and get component score coefficient matrix.

We can get factor score function according to the component score coefficient matrix in "Table III"

TABLE III. STANDARDIZED SCORING COEFFICIENTS

\begin{tabular}{|l|l|l|l|}
\hline & \multicolumn{1}{|c|}{ Factor1 } & \multicolumn{1}{|c|}{ Factor 2} & \multicolumn{1}{c|}{ Factor3 } \\
\hline $\mathrm{X} 1$ & 0.8432 & 0.1713 & -0.4705 \\
\hline $\mathrm{X} 2$ & 0.2001 & 0.6214 & 0.6086 \\
\hline $\mathrm{X} 3$ & 0.5052 & 2.5379 & -0.1688 \\
\hline $\mathrm{X} 4$ & 1.1494 & 1.1102 & 2.2849 \\
\hline $\mathrm{X} 5$ & 0.5496 & 1.4148 & 0.2635 \\
\hline $\mathrm{X} 6$ & 0.6006 & 1.3478 & 0.9893 \\
\hline $\mathrm{X} 7$ & 0.2533 & 1.0379 & 1.0094 \\
\hline $\mathrm{X} 8$ & -0.5018 & -1.4246 & 0.0532 \\
\hline $\mathrm{X} 9$ & -1.2511 & -2.2355 & -0.4229 \\
\hline $\mathrm{X} 10$ & -1.6544 & -0.9875 & -2.7526 \\
\hline
\end{tabular}

$$
\begin{aligned}
f_{1}= & 0.8432 x_{1}+0.2001 x_{2}+0.5052 x_{3}+1.1494 x_{4}+0.5496 x_{5}+0.6006 x_{6} \\
& +0.2533 x_{7}+-0.5018 x_{8}+-1.2511 x_{9}+-1.6544 x_{10} \\
f_{2}= & 0.1713 x_{1}+0.6214 x_{2}+2.5379 x_{3}+1.1102 x_{4}+1.4148 x_{5}+1.3478 x_{6}+ \\
& 1.0379 x_{7}+-1.4246 x_{8}+-2.2355 x_{9}+-0.9875 x_{10} \\
f_{3}= & -0.4705 x_{1}+0.6086 x_{2}+-0.1688 x_{3}+2.2849 x_{4}+0.2635 x_{5}+0.9893 x_{6}+ \\
& 1.0094 x_{7}+0.0532 x_{8}+-0.4229 x_{9}+-2.7526 x_{10}
\end{aligned}
$$

According to the factor score function, principle factor $\mathrm{f} 1$ has high load on X4 variable, which is closely related to economic development. Principle factor $\mathrm{fl}$ is named as "economic development factor". Principle factor $f 2$ has high load on X3 variable, which reflects the population development. Principle factor $\mathrm{f} 2$ is named as "population development factor". Principle factor $\mathrm{f3}$ has high load on X10 variable, which reflects the resource and environment. Principle factor f3 is named as "resource and environment factor"

The score matrix of three factors in twelve cities of Hubei Province is obtained according to SAS performance results. The rank of urbanization development level in Hubei Province can be obtained after calculation in Excel through substituting evaluation function (2.1) "Table IV".

TABLE IV. FACtor SCORES OF 12 Cities IN Hubei Province

\begin{tabular}{|l|l|l|l|}
\hline \multicolumn{1}{|c|}{ Obs } & \multicolumn{1}{|c|}{ Factor1 } & \multicolumn{1}{c|}{ Factor2 } & \multicolumn{1}{c|}{ Factor3 } \\
\hline 1 & -0.0905 & -1.6536 & -0.6331 \\
\hline 2 & -0.01044 & -0.08683 & 0.65755 \\
\hline 3 & -0.10005 & -0.0538 & -0.31074 \\
\hline 4 & 0.01779 & 1.84589 & -1.40675 \\
\hline 5 & -0.08572 & 1.78921 & 1.41631 \\
\hline 6 & -1.05829 & -0.18836 & 1.29042 \\
\hline 7 & -1.74338 & -0.23284 & -1.44528 \\
\hline 8 & 0.1116 & 0.06194 & 0.10751 \\
\hline 9 & 0.34956 & -0.86022 & 0.97144 \\
\hline 10 & -0.31942 & -1.2957 & -0.08344 \\
\hline 11 & 0.53655 & -0.93074 & -0.76209 \\
\hline 12 & 2.3018 & -0.04854 & -0.43494 \\
\hline
\end{tabular}

Overall scores reflect the urbanization level of twelve cities in Hubei Province. "Table V" indicates twelve cities of Hubei Province in 2014 present obvious polarization. The overall scores of urbanization level of Wuhan, Yichang and Huangshi ranks top three. Wuhan has the highest level, showing abundant industrial strength. The overall scores of Suizhou,
Jingmen, Ezhou, Xianning, Huanggang and Xiaogan are negative, indicating the comprehensive competitiveness of them is below the average of urbanization level in twelve cities of Hubei Province.

TABLE V. FACTOR SCORE OF 12 CITIES IN HubeI ProvinCE

\begin{tabular}{|l|l|l|l|l|l|}
\hline & Factor I & Factor II & Factor III & Overall score & Ranking \\
\hline Wuhan & 1.1518 & -0.0081 & -0.0822 & 1.0615 & 1 \\
\hline Yichang & -0.0429 & 0.2977 & 0.2677 & 0.5225 & 2 \\
\hline Huangshi & 0.1749 & -0.1431 & 0.1836 & 0.2154 & 3 \\
\hline Shiyan & -0.0052 & -0.0144 & 0.1243 & 0.1046 & 4 \\
\hline Xiangyang & 0.0558 & 0.0103 & 0.0203 & 0.0865 & 5 \\
\hline Jingzhou & 0.0089 & 0.3072 & -0.2659 & 0.0502 & 6 \\
\hline Suizhou & 0.2685 & -0.1549 & -0.1440 & -0.0304 & 7 \\
\hline Jingmen & -0.0501 & -0.0090 & -0.0587 & -0.1177 & 8 \\
\hline Ezhou & -0.5296 & -0.0313 & 0.2439 & -0.3170 & 9 \\
\hline Xianning & -0.1598 & -0.2156 & -0.0158 & -0.3912 & 10 \\
\hline Huanggang & -0.0453 & -0.2752 & -0.1197 & -0.4401 & 11 \\
\hline Xiaogan & -0.8724 & -0.0387 & -0.2732 & -1.1843 & 12 \\
\hline
\end{tabular}

In the ranking of resource and environment factor, Wuhan, Xiangyang and Huangshi rank the top, indicating these cities have good performance in sustainable development of urbanization and enormous potential of urbanization. In the ranking of economic benefit factor, other cities in Hubei Province lag behind Wuhan, indicating Wuhan City has the best economic benefits and other cities need improvement in it. In the ranking of population development, Yichang and huangshi take the lead, indicating they pay attention to the quality of population in urbanization.

\section{Suggestions to Improve the Urbanization Level of Twelve Cities in Hubei Province}

At present, the urbanization of twelve cities of Hubei Province develops rapidly. Urbanization is the comprehensive economic and social development and reform, not population transfer but inevitable result of economic and social 
development and the dynamic development of population, industry, economy, culture and social formation. The social formation transforms from the traditional rural society into modern urban society. It has profound influences on rural regional natural landscape, product and industrial structure, production method and life style, social organization system and administrative management system. We must adjust and reform production, life, economy, society, mechanism and system. According to the internal requirements of urbanization development, we must carry out it suitable for local development.

\section{1) Pay attention to the growth of city gene through} economy

In promoting the urbanization development, Hubei must attach special importance to the growth of city gene. First, exert the economic radiation function of Wuhan on surrounding cities and form the economic development circle centering on Wuhan. Second, give play to function of Yichang and Xiangfan. The two cities must scale up, improve the functions and strengthen regional radiation and competitiveness, build competitive industries, intensify economic strength as well as drive regional development. Third, depend on Yangtze River, accelerate the economic development in coastal areas of Yangtze River and construct the Yangtze River Economic Zone into one of the areas with convenient transportation, perfect facilities, good ecology, developed industry, prosperous market, urban-rural coordination, harmonious society, the strongest carrying capacity and the highest degree of industrial agglomeration and the strongest driving ability and sustainable development capacity.

2) Vigorously promote the agglomeration of production factors through industries

The prosperity and development of industrial economy is the support of urbanization construction. Different industrial structures vary in promoting new-type urbanization development. We should give full play to characteristics of different industries and develop local industries according to local conditions. Specifically speaking, there are three ways: first, develop skill-intensive and capital-intensive industries to improve urban competitiveness; second, develop laborintensive industry and consider urban labor employment and social stability; last, promote the urbanization of industrial structure and realize the comprehensive and coordinated development of urbanization.

\section{3) Strengthen the urban-rural coordination layout through planning}

Scientific planning is the premise of scientific development. New-type urbanization development must be guided by scientific planning. First, we must change the traditional planning layouts of "valuing cities instead of towns" and "urban-rural division". Planning department carries out urban and rural planning, accelerate the extension of planning management function to villages and construct the planning management system that covers town and country, realize the integration and coverage of urban and rural planning, promote the development of urban and rural integration. Second, improve the urban-rural planning level and guarantee the urban and rural planning is scientific. Third, strengthen the coordination and consistency of planning and carry out the integration of urban-rural planning system. Last, strengthen the authority and execution power of planning, especially the approval procedure with strict planning, to strengthen the informatization construction, improve supervision system and maintain the seriousness of urban-rural planning.

\section{CONCLUSION}

At present, no standard methods exist in the academic world to define local city. There are few researches on urbanization level and development type of local cities. On one hand, this paper defines local cities in Hubei Province from politics, economics, history and culture from a new perspective, but it is confined to feature description and contrastive analysis. More accurate definition methods remain to be researched. On the other hand, this paper builds the evaluation system for urbanization level of local cities in Hubei Province from the nature of new-type urbanization, discusses development types and paths of local cities and reaches heuristic conclusion. However, because of the complexity of town development, it only carries out static analysis on the development features of local cities from one perspective and fails to discuss the dynamic changes of development in each city from the time dimension. Furthermore, the researches on development of single city should be deepened. Restricted by the availability of statistical material, this paper fails to consider the representative indicators that cannot be quantified when building indicator system. Instead, it is replaced by indicators with similar symbolic meaning and easy quantification. How to further use scientific and effective methods to express these indicators accurately and build comprehensive and perfect indicator system will be researched.

\section{REFERENCES}

[1] Guo Junhua, Li Haigang. Construction and Evaluation of Performance Indicator System in Regional Urbanization-Take Western Region as an Example [J], Journal of Information, 2011, 07: 201-207

[2] Li Xingjiang, Meng Qiumin. Regional Comprehensive Urbanization Indicator System and Evaluation [J], Journal of Northwest Normal University (Natural Science), 2006, 01: 74-80+85

[3] Guo Guofeng, Yang Jinlu. Comprehensive Comparative Research on Urbanization Levels of Twelve Cities in Hubei Province [J], On Economic Problems, 2008, 11: 28-31+108

[4] Zeng Guang, Zhou Ji. Calculation and Analysis on Indicators of Powerful Industrial Provinces of China-Based on Factor Analysis and Cluster Analysis [J], Journal of Industrial Technological Economics, 2015, 10: 51-58

[5] Gao Ping. Acceleration of Urbanization Process Is the Inevitable Course for Sharp Rising of Central Region-Discussion on Three Strategic Transformation in the Development of Central Region [J], Jianghan Tribune, 2004, 12: 19-21

[6] Yang Jianren, Liu Weidong. Empirical Research on Urbanization Level of Twelve Cities in Hubei Province-Comprehensive Evaluation Based on Gray Connection [J], East China Economic Management, 2010, 01: 40-43 